\title{
H.-C. Lin, D.-L. Ren, Q.-L. He, H. Peng, S.-K. Xie, D. Su, X.-X. Wang: Partial stapled hemorrhoidopexy versus circular stapled hemorrhoidopexy for grade III-IV prolapsing hemorrhoids: a two-year prospective controlled study
}

\section{T. Khubchandani}

Received: 4 April 2012/Accepted: 4 April 2012/Published online: 31 August 2012

(C) Springer-Verlag 2012

Dr. Lin and his associates have described a novel modification-partial stapled hemorrhoidectomy (PSH), suggesting its superiority over the conventional circular stapled hemorrhoidectomy (CSH) [1].

The thesis justifying the technique is stated to be that partial resection with sparing of the mucosal bridges forms an elastic ring to enable a better rectal compliance with resultant improvement in postoperative symptoms. However, the mucosal bridges were dissected using electrocautery and the "dog ears" ligated. I wonder why the authors felt that to be necessary.

Although the authors have provided references, closed hemorrhoidectomy is performed by about $90 \%$ of North American colon and rectal surgeons. That technique has been dismissed as not having any advantage in postoperative pain reduction.

Further, there was no significant difference in the VAS between those who required skin tag excision and those who did not. Although the statement is supported by a reference, simple logic would indicate otherwise.
It is hard to accept the explanation that PSH, compared with $\mathrm{CSH}$, excises more prolapsing rectal mucosa longitudinally, resulting in a possible reduction in the recurrence rate. Also, the incidence of anal stenosis after $\mathrm{CSH}$ is suggested to be due to removal of large areas of anoderm. If the technique is performed correctly, there should be no anoderm removed at all.

The authors should be complimented for devising a new technique and providing a 2-year follow-up. It would be interesting to see how well it is adopted more universally.

Conflict of interest None.

\section{Reference}

1. Lin HC, Ren DL, He QL et al (2012) Partial stapled hemorrhoidopexy versus circular stapled hemorrhoidopexy for grade III-IV prolapsing hemorrhoids: a two-year prospective controlled study. Tech Coloproctol. doi:10.1007/s10151-012-0815-8

An author's reply to this comment is available at doi 10.1007/s10151-012-0864-z.

I. T. Khubchandani $(\square)$

Allentown, PA, USA

e-mail: indru.khubchandani@1vhn.org; indruk@aol.com 